\title{
A TERCEIRIZAÇÃO NA SAÚDE PÚBLICA: FORMAS DIVERSAS DE PRECARIZAÇÃO DO TRABALHO
}

\author{
THE OUTSOURCING IN PUBLIC HEALTH:VARIOUS FORMS OF PRECARIZATION OF LABOR \\ LA TERCERIZACIÓN EN SALUD PÚBLICA: DIVERSAS FORMAS DE PRECARIZACIÓN DEL TRABAJO
}

Graça Druck ${ }^{1}$

Resumo Apresentam-se, neste ensaio, algumas reflexões sobre a terceirização no serviço público a partir da ótica da sociologia do trabalho. Toma-se como referência a implantação das organizações sociais, que se tornou forte realidade na saúde pública nos últimos 15 anos, e que, a partir de 2015, por decisão do Supremo Tribunal Federal, foi validada como constitucional, com o que se negou o pedido de ação direta de inconstitucionalidade. Dessa forma, liberou-se a terceirização para todos os serviços essenciais sob responsabilidade do Estado. Também é objeto de discussão a implantação da Empresa Brasileira de Serviços Hospitalares, que, embora mais recente que as organizações sociais, já apresenta resultados tão nocivos quanto elas. A tese defendida é que a terceirização do serviço público no Brasil é um dos mecanismos mais eficientes de desmonte do conteúdo social do Estado e de sua privatização, que ocorre mediante formas diversas de precarização do trabalho, pois a terceirização - por meio de organizações sociais, organizações da sociedade civil de interesse público, empresas privadas, empresas públicas de direito privado, parcerias, dentre outras - é o meio principal que as forças políticas neoliberais encontraram para atacar o coração de um Estado social e democrático: os trabalhadores que constituem o funcionalismo público.

Palavras-chave terceirização; serviço público; organizações sociais; precarização do trabalho.
Abstract This essay presents some reflections on outsourcing in the public service inspired by the sociology of work. It takes as reference the implementation of social organizations, which became strong reality in public health over the past 15 years and, from 2015. After the decision of the Brazilian Supreme Court in 2015, it has been considered constitutional, denying the request for direct unconstitutionality action. Thus, released to outsourcing for all essential services under state responsibility. It is also the subject of discussion the implementation of the Brazilian Hospital Services Company (Empresa Brasileira de Serviços Hospitalares), which, although more recent than social organizations, already has such harmful results as them. The argument put forward is that the outsourcing of public service in Brazil is one of the most efficient mechanisms to remove the social content of the state and its privatization, which occurs through various forms of precarious work as outsourcing - through social organizations, civil society organizations of public interest, private companies, public companies under private rules, partnerships, among others - is the main way that neoliberal political forces found to attack the heart of a social and democratic state: the workers who are civil servants.

Keywords outsourcing; public service; social organizations; precarization of labor. 


\section{Introdução}

Os estudos realizados nos últimos 25 anos sobre a terceirização no Brasil ${ }^{2}$ foram unânimes em revelar a degradação do trabalho em todas as suas dimensões: no desrespeito aos direitos trabalhistas, nas más condições de trabalho, nos baixos salários, na piora das condições de saúde, nos maiores índices de acidentes e na vulnerabilidade política dos trabalhadores que, dispersos e fragmentados, têm dificuldades para se organizar coletivamente.

As pesquisas sobre terceirização indicam que a precarização social do trabalho, além de se tornar uma temática central dos estudiosos, revela-se uma estratégia de dominação que atinge a todos os trabalhadores, mesmo que de forma diferenciada e hierarquizada, como parte da dinâmica de desenvolvimento do capitalismo flexível no contexto da globalização e da hegemonia neoliberal.

A centralidade do trabalho e suas formas históricas justificam o caráter 'social' da precarização. Porém, para além dessa questão de fundo, a precarização do trabalho é 'social' porque: a) torna-se uma estratégia de dominação do capital num determinado momento histórico, combinando a crise do fordismo e dos Estados de bem-estar-social à financeirização da economia, às políticas neoliberais e à reestruturação produtiva, que formam um novo regime de acumulação flexível; b) é geral, no sentido de que é um processo mundial, conforme já afirmado, mas também porque rompe determinadas dualidades, a exemplo dos excluídos e incluídos, empregados e desempregados, formais e informais, público e privado, pois há um processo de precarização que se generaliza para todos os diferentes segmentos de trabalhadores, mesmo que de forma hierarquizada, estabelecendo-se uma 'institucionalização da instabilidade' (Thébaud-Mony, 1997); c) as implicações das transformações do trabalho atingem todas as demais dimensões da vida social: a família, o estudo, o lazer e a restrição do acesso aos bens públicos (especialmente saúde e educação); e d) expressa-se não apenas no âmbito do mercado de trabalho (contratos, inserção ocupacional, níveis salariais), mas em todos os campos, como na organização do trabalho e nas políticas de gestão, nas condições de trabalho e de saúde, nas formas de resistência e no papel do Estado (Druck, 2014).

Um conjunto de indicadores e dimensões da precarização social do trabalho foi objeto de análise para demonstrar como ela se manifesta na realidade. São eles: 1) as formas de mercantilização da força de trabalho (o mercado de trabalho); 2) os padrões de gestão e organização do trabalho; 3) as condições de (in)segurança e saúde no trabalho; 4) o isolamento e a perda de enraizamento e de vínculos resultantes da descartabilidade, da desvalorização e da discriminação, afetando decisivamente a solidariedade de 
classe; 5) o enfraquecimento da organização sindical e das formas de luta e representação dos trabalhadores; e, por fim, 6) a 'crise' do direito do trabalho motivada pela ofensiva patronal, que questiona a sua tradição e existência, expressa hoje nos ataques à Consolidação das Leis do Trabalho (CLT), a exemplo das 101 propostas de modernização trabalhista formuladas pela Confederação Nacional da Indústria (CNI) ou do projeto de lei $\mathrm{n}^{\circ} 4.330$, proposto e defendido pelo empresariado, que libera a terceirização sem limites.

A terceirização é um fenômeno que incorpora e sintetiza essas seis dimensões da precarização social do trabalho no país, pois invariavelmente ela coincide com posições mais precárias de inserção no mercado de trabalho; apresenta as piores condições de trabalho e salariais, e os mais altos índices de acidentes de trabalho; contribui decisivamente para aumentar a heterogeneidade e a fragmentação da classe trabalhadora e para a pulverização dos sindicatos; e está no centro da disputa do patronato com o Estado regulador, que busca anular a ação das instituições do direito do trabalho e do seu papel protetivo dos trabalhadores na relação capital-trabalho (Druck, 2014).

Cabe observar, no entanto, que, a despeito da existência de um vasto campo de estudos sobre precarização e terceirização nas duas últimas décadas no Brasil, poucas são as pesquisas sobre a terceirização no serviço público no campo da sociologia do trabalho.Há estudos sobre terceirização nas empresas públicas, que são parte do que se chama de setor público caso da Petrobrás, Banco do Brasil, por exemplo -, mas são raros os que investigam os serviços públicos. Essa é uma lacuna na sociologia do trabalho brasileira.

A maior parte dos estudos tem por objeto a discussão sobre a regulamentação, os limites constitucionais e o crescimento da terceirização, assim como os casos ilícitos e que ferem os princípios constitucionais da responsabilidade do Estado sobre os serviços públicos. Todos eles se situam no campo do direito do trabalho e constituem preciosa contribuição para a compreensão dos limites, das incongruências e do desrespeito à legislação e à Constituição, mas, sobretudo, ajudam a desvendar os mecanismos e instrumentos da privatização do Estado e dos serviços públicos, fornecendo rico material para se compreender a reforma do Estado brasileiro sob as diretrizes do neoliberalismo.

Nessa medida, pretende-se, neste ensaio, apresentar algumas reflexões inspiradas na sociologia do trabalho sobre a terceirização no serviço público, a partir da implantação das organizações sociais (OSs) - lei n ${ }^{\circ}$ 9.637/1998 -, que se tornou forte realidade na saúde pública nos últimos quinze anos. E que, a partir de 2015, com decisão do Supremo Tribunal Federal (STF), foi validada como constitucional, negando-se o pedido de ação direta de inconstitucionalidade (ADI) e sendo liberado, dessa forma, a terceirização para todos os serviços essenciais sob responsabilidade do Estado: saúde, educação, cultura, ciência e tecnologia, desporto/lazer e meio ambiente. Será também objeto de discussão a implantação da Empresa Brasileira de Serviços Hospitalares (EBSERH). 
A hipótese é de que a terceirização do serviço público no Brasil, além de ser um dos mecanismos mais importantes e eficientes de desmonte do conteúdo social do Estado e de sua privatização, é a via que o Estado neoliberal encontrou para pôr fim a um segmento dos trabalhadores, o funcionalismo público, que tem papel crucial para garantir o direito e o acesso aos serviços públicos necessários à sociedade, e sobretudo à classe trabalhadora, impossibilitada de recorrer a esses serviços no mercado. São várias as modalidades de ataques aos direitos, ao padrão salarial e às condições de trabalho do funcionalismo, consubstanciadas nos ajustes fiscais implantados pelos vários governos desde o início dos anos 1990 até hoje, ajustes esses recomendados e exigidos pelas instituições e classes que representam o capital financeiro globalizado. A proliferação da terceirização em serviços públicos essenciais, como é o caso da saúde, resulta na diminuição do número de funcionários e em sua desqualificação e desvalorização, em prol de uma suposta - e não comprovada - eficiência de instituições de natureza privada, mais flexíveis e ágeis, em contraposição ao padrão do serviço público brasileiro.

Na realidade, o que se observa é que o serviço público no país vem sendo gravemente prejudicado pela falta de investimento e valorização do funcionalismo, expressa nas reformulações dos planos de carreira e nas reformas da previdência social, nos salários defasados (especialmente nas áreas de educação e saúde), na falta de políticas de qualificação e treinamento, e na ausência de incentivos morais e materiais, que, ao lado da prática da terceirização - uma das formas mais precárias de trabalho -, fragiliza a função e a identidade do 'servidor público', atingindo diretamente o conjunto da sociedade brasileira (Druck, 2013).

\section{As formas de terceirização no serviço público}

Sem a pretensão de uma definição rigorosa sobre as modalidades de terceirização no serviço público, é objetivo contextualizar sócio-historicamente as origens e o seu desenvolvimento. Um marco na regulamentação é o ano de 1967, quando o governo militar empreendeu uma reforma administrativa do aparelho de Estado, "com o objetivo de impedir o crescimento desmesurado da máquina administrativa" (Decreto-lei 200/1967, art.10,§7º), descentralizando suas atividades, por meio da subcontratação (ou terceirização) de serviços, chamada de "execução indireta, mediante contrato"(.(Decreto-lei 200/1967, art.10,§7º) Entretanto, o uso da terceirização foi limitado, pois não havia exigência constitucional de concurso público para o contrato de funcionários públicos, os quais, regidos pela CLT, podiam ser admitidos e demitidos facilmente. Isso se alterou com a Constituição de 
1988, pois o concurso público se tornou obrigatório para cargo e emprego público (Amorim, 2009).

A aprovação da nova Constituição brasileira coincidiu com o início da implantação das políticas neoliberais, para a qual a expansão da terceirização é um marco importante: os programas de privatização de empresas e de serviços públicos criados nos anos 1990 e a reforma do Estado iniciada em 1995, com o Plano Diretor de Reforma do Aparelho de Estado, de responsabilidade do Ministério da Administração Federal e Reforma do Estado (Mare).

Amorim (2009) destaca, com razão, a justificativa exposta no Plano Diretor, que defende uma administração pública gerencial que se espelha na administração da empresa flexível do regime toyotista, visto que: "o paradigma gerencial contemporâneo [...] exige formas flexíveis de gestão, horizontalização de estruturas, descentralização de funções, incentivos à criatividade" (Plano Diretor de Reforma do Aparelho de Estado, apud Amorim, 2009, p. 71).

Uma reforma condizente com as políticas neoliberais, que definiu três áreas de atuação: a) as atividades exclusivas do Estado, constituídas pelo núcleo estratégico; b) os serviços não exclusivos do Estado (escolas, universidades, centros de pesquisa científica e tecnológica, creches, ambulatórios, hospitais, entidades de assistência aos carentes, museus, orquestras sinfônicas, dentre outros), que deveriam ser publicizados; e c) a produção de bens e serviços para o mercado (com a retirada do Estado mediante adoção de programas de privatização e desestatização). Fora das atividades principais, estão as 'atividades ou serviços auxiliares' (limpeza, vigilância, transporte, serviços técnicos de informática e processamento de dados, entre outros), que deveriam ser terceirizados e submetidos à licitação pública (Departamento Intersindical de Estatística e Estudos Socioeconômicos, 2008).

Na linha da reforma do Estado, a Lei de Responsabilidade Fiscal, de $2000,{ }^{3}$ cujo objetivo principal para o controle das contas públicas é reduzir as despesas com o funcionalismo público, inibiu a realização de concursos públicos e incentivou a terceirização, pois as despesas com a subcontratação de empresas e com a contratação temporária, emergencial e de comissionados não são computadas como despesas com pessoal.

Com isso, criou-se e ampliou-se a diversidade de modalidades de terceirização na esfera pública, a exemplo de: concessão, permissão, parcerias, cooperativas, organizações não governamentais (ONGs), OSs e organizações da sociedade civil de interesse público (Oscips). Constituiu-se assim um quadro em que parte dos serviços públicos é realizada não mais pelo servidor público, profissional concursado, mas pelos mais diferentes tipos de trabalhadores, em geral empregados de forma precária, com contratos por tempo determinado, por projetos, sem os mesmos direitos que o funcionário público (Druck, 2013). 
Essas modalidades podem enquadrar o que Pochmann (2008) denomina de 'superterceirização', fenômeno observado no setor privado pelo autor, quando as empresas passam a terceirizar 'atividades-fim', ou seja, aquelas que são nucleares no processo produtivo. Para Amorim (2009), esse mesmo processo ocorre no serviço público, quando a terceirização atinge atividades que são de responsabilidade do poder público. Essa situação se revela nos relatórios do Tribunal de Contas da União (TCU) sobre as contas do governo, constatando vários casos em que atividades-fim, como fiscalização e controle do serviço público, estavam sendo terceirizadas, e não somente aquelas atividades acessórias, instrumentais e complementares. Ou seja, caracteriza-se o descumprimento à própria lei que instituiu as OSs e ao decreto-lei que definiu que não poderiam ser terceirizadas as atividades

inerentes às categorias funcionais abrangidas pelo plano de cargos do órgão ou entidade, salvo expressa disposição legal em contrário ou quando se tratar de cargo extinto, total ou parcialmente, no âmbito do quadro de pessoal (Decreto-lei $\mathrm{n}^{\mathrm{o}}$ 2.271/1997 apud Amorim, 2009, p. 124).

Os casos citados no relatório do TCU de 2001, apud Amorim, 2009, referem-se ao Instituto Brasileiro do Meio Ambiente e dos Recursos Naturais Renováveis (Ibama), ao Departamento Nacional de Estradas de Rodagem (DNER), que terceirizava a atividade de fiscalização ambiental, por exemplo, ou de estradas, assim como à terceirização pelo Instituto Nacional do Seguro Social (INSS) de atividades de habilitação, concessão e formatação de benefícios, que são atividades-fim do instituto (Amorim, 2009, p. 72).

Além desses aspectos, outro, tão importante quanto, é o volume de recursos pagos pelos serviços subcontratados ou terceirizados. Embora não existam dados sistematizados sobre o custo da terceirização na administração pública, os relatórios do TCU, mais uma vez, são uma fonte preciosa. Em 2004, destacavam o aumento dos gastos com terceirização em comparação com o custo do funcionário público, a exemplo do que ocorria no então Ministério do Desenvolvimento Social e Combate à Fome, cujas despesas com pessoal terceirizado representavam $410 \%$ das despesas com o pessoal próprio; do Ministério do Turismo, com 185\%; do Ministério dos Esportes, 159\%; dos ministérios de Desenvolvimento Social e Comércio, 110\%; e do Ministério da Defesa, 82\% (Amorim, 2009, p. 73).

\section{A terceirização por meio das organizações sociais: o caso da saúde pública}

A terceirização que vem ocorrendo no serviço público de saúde é exemplar para indicar a renúncia do Estado à sua responsabilidade social e, ao mesmo 
tempo, revelar a promiscuidade das relações público-privado, com a transferência de altas somas de recursos públicos para instituições privadas, sem qualquer avaliação, planejamento, supervisão ou controle de como esse recurso é utilizado e de quais serviços e por quem e em quais condições estão sendo prestados, conforme atestam as auditorias realizadas pelo TCU em 2012, fonte principal da análise que se apresentará a seguir.

As OSs foram propostas no quadro da reforma do Estado, conforme definido pelo Plano Diretor de Reforma do Aparelho de Estado, no programa de publicização para os serviços não exclusivos do Estado - atividades que são exercidas

simultaneamente pelo Estado e pela esfera privada, mas que devem ser fomentadas pelo poder público em função de serem relacionadas a direitos humanos fundamentais ou gerarem economias externas relevantes, como saúde, educação, assistência social, cultura (Tribunal de Contas da União, 2012, p. 4).

Essa 'publicização' permitia a transferência dos serviços do setor estatal para o público não estatal, no qual assumiriam a forma de organizações sociais. O pressuposto para a descentralização de atividades no setor de prestação de serviços não exclusivos era "de que esses serviços seriam mais eficientemente realizados se, mantendo o financiamento do Estado, fossem realizados pelo setor público não estatal, que corresponde às entidades do terceiro setor, sem fins lucrativos" (Tribunal de Contas da União, 2012, p. 4).

As OSs foram criadas pela lei federal $n^{\circ} 9.637 / 1998$, que estabelece, em seu artigo $1^{\circ}$ :

O Poder Executivo poderá qualificar como organizações sociais pessoas jurídicas de direito privado, sem fins lucrativos, cujas atividades sejam dirigidas ao ensino, à pesquisa científica, ao desenvolvimento tecnológico, à proteção e preservação do meio ambiente, à cultura e à saúde, atendidos aos requisitos previstos nesta lei (Brasil, 1998).

Nesse mesmo ano de 1998, o Partido dos Trabalhadores (PT) e o Partido Democrático Trabalhista (PDT) entraram com uma ação direta de inconstitucionalidade, a ADI 1.923, na qual solicitavam a suspensão cautelar de artigos da lei até que fosse julgada a ação. Em 2007, o Supremo Tribunal Federal rejeitou o pedido cautelar, mas não julgou a ADI; portanto, a lei seguiu em curso, mesmo que sob suspeição. Tal situação permitiu que as OSs fossem implantadas, sobretudo na saúde pública.

As fontes de dados sobre a evolução quantitativa das OSs no Brasil são dispersas e não há uma sistematização das informações. Entretanto, estudos 
acadêmicos publicados, relatórios e auditorias do TCU, algumas Comissões Parlamentares de Inquérito (CPIs) estaduais e estatísticas do Instituto Brasileiro de Geografia e Estatística (IBGE) para os municípios e estados brasileiros nos permitem tecer algumas considerações sobre elas.

De acordo com o perfil dos estados e dos municípios brasileiros, elaborado pelo IBGE (2014), que atingiu os 27 estados e 5.570 municípios existentes (até dezembro de 2014), a evolução do quadro dos funcionários municipais por vínculo empregatício mostrou que, em 1999, os estatutários representavam $65 \%$ do total, caindo para $61,1 \%$ em 2014. Em contrapartida, o pessoal sem vínculo empregatício passou de 13,4\% para 18,7\% nesse período.

No caso dos funcionários públicos estaduais, entre 2012 e 2014 houve um decréscimo de cerca de 137.268 estatutários estaduais (-5,9\%), enquanto os servidores sem vínculo (não concursados e não permanentes) tiveram um acréscimo de 151.553, passando de cerca de 418.850 para 570.403 nesse período, ou seja, apresentaram um crescimento de $36,2 \%$. Considerando que a contratação de OSs é feita essencialmente pelos municípios e estados, pode-se inferir que essa evolução do quadro de pessoal reflete o processo de terceirização adotado, no qual as OSs têm predominância.

O estudo do IBGE de 2014 analisou o quadro do funcionalismo para a saúde pública nos municípios e nos estados. No caso da administração municipal, o número de pessoas ocupadas na área de saúde era de 1.574 .318 entre os 5.513 municípios que forneceram a informação, representando $24 \%$ do total de pessoal ocupado na administração municipal brasileira. O pessoal ocupado sem vínculo permanente na saúde representava $28,6 \%$ do total de pessoal sem vínculo permanente da administração municipal e tinham $27 \%$ celetistas e $23,1 \%$ estatutários em relação ao total do serviço público municipal. No quadro de pessoal na saúde nos municípios, a distribuição do pessoal segundo o vínculo empregatício era de 58,5\% estatutários, $11,4 \%$ celetistas, $5 \%$ comissionados e $22 \%$ trabalhadores sem vínculo permanente em 2014.

No que se refere aos modos de gestão na saúde, a pesquisa mostrou que cerca de $88 \%$ (4.924) dos municípios brasileiros possuem estabelecimentos de saúde sob sua responsabilidade de gestão. Desse total, 10,6\% (522) dos municípios possuíam estabelecimentos administrados por terceiros. E de um total de 2.316 unidades terceirizadas, 
cerca de $43 \%$ eram administrados por organizações sociais (OSs); 28,4\%, por empresas privadas; $18,2 \%$, por consórcios públicos; $5,7 \%$, por organizações de sociedade civil de interesse público (Oscips); 3,2\%, por cooperativas; e 1,3\%, por consórcios de sociedade" (Instituto Brasileiro de Geografia e Estatística, 2014, p. 54; grifos meus).

$\mathrm{Na}$ análise das diferentes regiões brasileiras, destacam-se as regiões $\mathrm{Su}$ deste e Sul, cuja proporção de instituições terceiras era de, respectivamente, $18,6 \%$ e 12,9\%. No Sudeste, as organizações sociais eram responsáveis por cerca de $67 \%$ dos estabelecimentos administrados por terceiros e as empresas privadas, por aproximadamente $13 \%$, enquanto nas regiões Norte, Nordeste, Sul e Centro-Oeste, as organizações sociais respondiam por, respectivamente, $5,1 \%, 8,7 \%, 19,0 \%$ e $12,5 \%$.

Segundo o IBGE (2014, p. 55), o peso das OSs no total de serviços terceirizados é diretamente proporcional ao tamanho da população, pois em $41 \%$ dos municípios com mais de 500 mil habitantes, cerca de $88 \%$ dos estabelecimentos terceirizados eram administrados por OSs.

Esse conjunto de informações corrobora outras, como as de Andreazzi e Bravo (2014), quando informam que, em 2007, das 70 OSs criadas no país, 25 (36\%) estavam na saúde pública e, delas, 16 (64\%) em São Paulo. Ou no caso do Rio de Janeiro, onde, em 2011, das 37 instituições classificadas como sem fins lucrativos, 21 (57\%) eram da área de saúde.

Também dentre as conclusões do Relatório de Auditoria Operacional do TCU, constatou-se o crescimento da terceirização por meio das OSs:

A terceirização das ações e serviços de saúde é uma medida adotada por um número cada vez maior de entes federativos. O poder público está deixando de gerenciar hospitais, unidades básicas de saúde, equipes da saúde da família e outros serviços, transferindo esta incumbência para entidades privadas (Tribunal de Contas da União, 2012, p. 65).

A experiência da terceirização no serviço público de saúde com a implantação das OSs demonstra cabalmente que há uma transferência de recursos públicos para instituições e empresas privadas, a fim de assumirem um serviço essencial à sociedade brasileira, que é um dever constitucional do Estado.

Embora comandada pela lei $n^{\circ} 9.637 / 1998$, que instituiu as OSs, a administração pública em todos os níveis - municipal, estadual e federal - não está cumprindo absolutamente nenhuma das exigências da referida lei. É o que revela a auditoria realizada pelo TCU em 2012, que merece ser aqui documentada e comentada, pois a sua avaliação leva a questionar a 
terceirização num serviço público essencial, como é o caso da saúde, assim como legitima e valida todos os argumentos para a sustentação de uma ADI.

\section{Os principais 'achados' da auditoria do TCU: a terceirização sem limites}

Na apresentação dos resultados da auditoria, o relatório do TCU decidiu por tematizar o que encontrou nas instituições auditadas, com a justificativa de que os problemas se repetem, ou seja, são encontrados em todos os casos. As instituições auditadas foram: Ministério da Saúde, Secretaria Estadual de Saúde da Bahia, Secretaria Municipal de Saúde de Salvador, Secretaria Municipal de Saúde de Araucária, Secretaria Municipal de Saúde de Curitiba, Secretaria de Estado da Saúde de São Paulo, Secretaria Municipal de Saúde de São Paulo, Secretaria Municipal de Saúde e Defesa Civil do Rio de Janeiro, Secretaria Estadual de Saúde da Paraíba (Tribunal de Contas da União, 2012, p. 1). E os objetivos definidos foram assim expostos:

A terceirização dos serviços de saúde pode ser vista como um processo com diferentes fases. Procurou-se identificar o papel do poder público em cada uma delas, com vistas a apontar quais funções essenciais deveriam ser desempenhadas. A partir desta análise, foram definidas as seguintes questões de auditoria:

a) O processo decisório de transferência do gerenciamento de serviços de saúde para entidades privadas demonstra que esta é a melhor opção frente à prestação direta do serviço?

b) O processo de qualificação e seleção da entidade privada é objetivo e garante que seja escolhida a mais apta a prestar o serviço?

c) A formalização da parceria abrange os critérios necessários para garantir a prestação adequada do serviço e o seu controle?

d) O controle da execução do contrato garante a devida responsabilização pelos resultados alcançados e a regular aplicação dos recursos? (Tribunal de Contas da União, 2012, p. 3).

Em resposta a essas questões, os temas e itens expostos indicam claramente o que foi encontrado, conforme consta na parte "4. Achados das fiscalizações nas secretarias estaduais e municipais", que embasaram o voto do ministro relator, afirmando que: "Após examinar as informações e análises oferecidas pela equipe de auditoria, estou convicto de que a resposta é negativa para as quatro questões acima." (Tribunal de Contas da União, 2012, p. 73; grifos meus);

Com o objetivo de acompanhar os achados da auditoria, apresentam-se a seguir os principais itens que compõem o relatório. 
“4.1 O processo decisório pela terceirização não demonstra que ela é a melhor opção":

[...] em todos os casos que integraram o escopo da presente auditoria, nenhum dos processos de seleção apresentou estudo ou ensaio capaz de demonstrar eventuais vantagens na gestão pelo modelo privado. Nos estados da Bahia e São Paulo, bem como no município de São Paulo, as leis que regulam os programas de publicização contêm determinação expressa quanto à realização de tais estudos.

[...] observou-se que os processos de seleção e contratação das entidades para a gestão terceirizada carecem da simples estimativa orçamentária que deve integrar os autos de qualquer processo do qual resultará a aplicação de recursos públicos [...] (Tribunal de Contas da União, 2012, p. 24).

No caso do município de São Paulo:

O contrato 6/2008-NTCSS/SMA se iniciou com o valor anual de R\$ 10 milhões e durante a realização da auditoria apresentava valor aproximado de R\$ 120 milhões. O contrato 9/2008-NTCSS/SMS iniciou-se com R\$ 10 milhões anuais e alcançava o valor de R $\$ 44$ milhões de custeio. Deve-se observar que os dois contra tos mencionados foram julgados irregulares pelo Tribunal de Contas do Município de São Paulo e apresentavam irregularidades graves na sua execução. (Tribunal de Contas da União, 2012, p. 26).

No caso do estado da Bahia:

Na Secretaria Estadual da Saúde da Bahia (SES-BA), dos nove processos de seleção de entidades para parcerias na gestão dos hospitais de rede estadual analisados, nenhum apresentou estudo ou ensaio capaz de demonstrar eventuais vantagens de economicidade ou produtividade na gestão da unidade hospitalar pelo modelo privado, em comparação com a gestão pelo regime jurídico aplicável à administração pública (Tribunal de Contas da União, 2012, p. 27).

“4.2. A qualificação e seleção das organizações sociais constitui em muitos casos mera formalidade, sem seguir critérios objetivos e que garantam que as entidades mais qualificadas serão escolhidas." (Tribunal de Contas da União, 2012, p. 29).

A qualificação e seleção das organizações sociais para assinatura do contrato de gestão apresentam uma série de falhas que comprometem a objetividade dos processos, dando margem a favorecimentos e à possibilidade de contratação de entidades sem as condições adequadas para gerenciamento dos serviços públicos de saúde. Em muitos casos, observa-se que os processos constituem mera formalidade com o objetivo de atender às disposições legais, mas que, na prática, 
pecam pela falta de critérios objetivos e análises detalhadas (Tribunal de Contas da União, 2012, p.29).

Nesse item, é registrada uma série de processos de contratação de OSs irregulares, denunciando a forma fraudulenta em que instituições privadas se apresentam como OSs, bem como a total falta de critérios e procedimentos do poder público para classificar tais instituições como OSs. Nas chamadas para a contratação - nem sempre tão públicas como deveriam ser - também são encontradas indicações de pessoalidade, favorecimento e cumplicidade.

Tais constatações levam a afirmar que as OSs são uma farsa, pois em todos os lugares auditados ficou visível que instituições privadas com fins lucrativos passam a intermediar contratos (precários) de trabalhadores, utilizando o patrimônio público para explorá-los, ou seja, sem qualquer investimento, pois recebem os hospitais prontos, aparelhados e já em funcionamento (com uma clientela garantida), recebendo altos valores de recursos que lhes são pagos pelo Estado. É o caso também de OSs recém-criadas que, mesmo sem nenhuma experiência na área, são escolhidas pela instituição pública, revelando-se apenas como intermediadoras de mão de obra, o que é ilegal e imoral. É a terceirização da terceirização praticada pelo Poder Público.

Para além desses casos de falsas OSs, foram encontrados também, nos municípios do Rio de Janeiro, Salvador e no estado da Bahia,

contratos com empresas privadas com fins lucrativos para gerenciarem hospitais públicos. Trata-se de modelo bastante semelhante com o das organizações sociais, pois uma unidade pública de saúde tem seu gerenciamento terceirizado, mas não existe legislação que autorize este tipo de ajuste (Tribunal de Contas da União, 2012, p. 40)

É a contratação de entidades privadas com fins lucrativos para gestão de unidades de saúde públicas sem fundamento legal ( Tribunal de Contas da União, 2012, p. 40).

A Secretaria de Estado da Saúde da Bahia (SES-BA) também mantém contratos com empresas privadas para gerenciamento de hospitais públicos. Há seis hospitais cuja gestão foi terceirizada por meio da contratação de serviços junto a empresas privadas - contratação regida pelas normas aplicáveis de licitações e contratos administrativos (Tribunal de Contas da União, 2012, p. 41).

No item "4.5. Ausência de indicadores ou dos atributos necessários para que a avaliação do desempenho da OS seja efetiva", a auditoria constatou 
ausência de qualquer indicador, ou, quando há algum, a inexistência de capacidade técnica para operacionalizá-lo. Todos os casos analisados mostram a necessidade de implantar controles e procedimentos que permitam uma real avaliação das OSs. Isso significa que o Estado não tem qualquer controle sobre custos, gastos, serviços e funcionários que as OSs estão empregando. É o uso da infraestrutura e dos recursos públicos de forma privada e sem qualquer transparência. A auditoria do TCU também verificou, em alguns casos, a falta de controle sobre a execução dos contratos de gestão, completando o quadro de descontrole já observado com a inexistência de avaliação das atividades e operações das OSs.

De acordo com a legislação, há exigência de constituição e participação de conselhos de saúde e de representantes da sociedade e usuários dos serviços no controle sobre as OSs. No entanto, o item 4.7 é conclusivo: “Desconsideração pelos gestores estaduais e municipais das instâncias de controle social" (Tribunal de Contas da União, 2012, p. 56). ${ }^{4}$ Há casos em que, quando consultados os conselhos de saúde, as suas recomendações não são atendidas, como aquelas nas quais se posicionam contra a terceirização, conforme registra o relatório:

Porém, além da falta de estudos prévios que demonstrem que a terceirização para organizações sociais é a opção mais vantajosa em cada um dos serviços transferidos, outro problema identificado no processo de decisão acerca da transferência ou não do gerenciamento dos serviços de saúde para entidades privadas é a falta de participação dos conselhos de saúde. Em muitos casos não há consulta às entidades de controle social, em outros há a manifestação contrária à terceirização, que não é atendida pelos gestores locais (Tribunal de Contas da União, 2012, p. 56).

Em síntese, os resultados em todas as instituições auditadas demonstraram que: a) a terceirização não prova ser a melhor opção, pois não há estudos sobre a situação nem antes nem depois da contratação das OSs; b) não há controle nem avaliação dos contratos e dos serviços; c) não há participação dos conselhos de saúde ou, quando há, são desconsiderados; d) não há critérios objetivos para a classificação das entidades como organizações sociais; e e) não há controle financeiro no repasse de recursos, o que é agravado pelo fato de a legislação definir que as OSs não precisam fazer licitação para contratar pessoal ou para a compra de bens.

Os fatos relatados pelo TCU são extremamente graves e suficientemente fortes para demonstrar que a terceirização no serviço público, por meio das OSs, precisaria ser imediatamente revertida. Infelizmente não foi essa a recomendação do TCU, que determinou um prazo de noventa dias para que o 
Ministério da Saúde orientasse os gestores federais, estaduais e municipais na adoção das providências necessárias para o cumprimento da lei e elaborasse "um normativo para regulamentar a participação das organizações sociais no SUS [Sistema Único de Saúde]". E todas as recomendações feitas diretamente aos municípios e estados auditados se resumiram em apontar as falhas e o necessário cumprimento da legislação. Conforme consta para todos os casos auditados:

recomendar [...] que o processo de transferência do gerenciamento dos serviços de saúde para organizações sociais seja precedido de estudo detalhado que contemple: (a) justificativa de que a transferência do gerenciamento para organizações sociais mostra-se a melhor opção; (b) avaliação precisa dos custos do serviço e ganhos de eficiência esperados da OS; (c) inclusão de planilha detalhada com a estimativa de custos a serem incorridos na execução dos contratos de gestão celebrados com organizações sociais e demonstrativo do cálculo das metas estabelecidas; (d) participação das esferas colegiadas do SUS (Tribunal de Contas da União, 2012, p. 68-70).

É como se a causa de todos os males revelados fosse a falta de regulamentação, quando no próprio relatório é evidenciado que, apesar da clareza dos dispositivos da lei das OSs, tem sido desrespeitada na sua totalidade. $\mathrm{Ou}$ que o problema seria resolvido com campanhas educativas e de treinamento dos gestores, como se a responsabilidade do fracasso das OSs na saúde pública fosse da forma de gestão e não do processo de terceirização. Ora, no relatório, no item "Terceirização das atividades finalísticas", lê-se:

O modelo de transferência do gerenciamento de unidades públicas de saúde para as organizações sociais também é contestado na Justiça do Trabalho, sendo considerada uma forma de terceirização de atividades finalísticas do Poder Público, o que seria ilegal. Ainda recentemente, em outubro de 2012, decisão judicial decretou a nulidade de todos os contratos de gestão celebrados pela Secretaria Estadual de Saúde de São Paulo e determinou a troca dos funcionários terceirizados por servidores concursados nos 37 hospitais e outras 44 unidades de saúde. Decisões semelhantes já foram tomadas em outras unidades da federação (Tribunal de Contas da União, 2012, p. 14).

Além disso, é citado o próprio TCU:

O TCU já se pronunciou acerca da legalidade do modelo em mais de uma ocasião. O acórdão 1.146/2003-TCU-Plenário julgou representação acerca de irregularidades na implementação do Programa Saúde da Família pelo governo do Distrito Federal, que estaria contratando pessoal sem concurso público, valendo-se da 
simulação de contrato de gestão com o Instituto Candango de Solidariedade. Ficou demonstrado que o instituto atuava apenas como mera pessoa interposta, para viabilizar a contratação de pessoal sem concurso público. A entidade não tinha atuação na área de saúde e sua tarefa no contrato seria apenas de fazer a seleção e gestão do pessoal (Tribunal de Contas da União, 2012, p. 14-15).

Em síntese, a experiência da terceirização no serviço público de saúde nos últimos quinze anos por intermédio das organizações sociais, além de mostrar um crescimento desmedido, tornando-as preponderantes e deixando de ser complementares, a exemplo de São Paulo, com contratos sem concursos e sem qualquer fiscalização da administração pública, deixam-nas livres para se constituírem em redes de subcontratação, isto é, a terceirização da terceirização, ou seja, sem limites, como quer o projeto de lei $\mathrm{n}^{\circ}$ 4.330, renomeado como (PL 30) no Senado.

Trata-se de um claro processo de precarização do serviço público, ${ }^{3}$ de uma transferência de patrimônio público para uso da iniciativa privada, como é o caso dos hospitais, de um alto custo financeiro para o Estado, com desvio de recursos, num ambiente promíscuo em que se confundem o privado e o público e com uma forma duplamente perversa de precarização do trabalho, pois, por um lado, cria um segmento de trabalhadores sem vínculos permanentes, com alta rotatividade e sem um conjunto de direitos e, por outro, vai destruindo os funcionários públicos, com a redução de seu tamanho e dos seus direitos, desqualificando e desvalorizando uma categoria profissional que é essencial num Estado democrático.

\section{A luta contra a terceirização hoje: o PL n 4.330 (PL 30) e a ADI 1.923}

Em de outubro de 2011, ocorreu em Brasília a Audiência Pública sobre Terceirização, convocada pelo Tribunal Superior do Trabalho (TST), na qual participaram 49 expositores, inclusive esta autora, entre representantes sindicais e patronais, instituições do direito do trabalho e estudiosos do tema, além dos ministros do Tribunal e de um público que teve a oportunidade de assistir as análises de cada um dos expositores pautadas em suas diferentes experiências e perspectivas. Foi a primeira audiência pública após setenta anos de existência do TST.

Os motivos para convocar essa audiência pública, a sua realização e seus impactos indicavam o grave quadro da terceirização no país: o que denominei de uma verdadeira epidemia sem controle, gerando uma situação de desrespeito aos direitos dos trabalhadores, resultando num alto volume de processos na Justiça do Trabalho. 
A audiência pública possibilitou o encontro e o intercâmbio entre vários profissionais ligados ao direito do trabalho, pesquisadores estudiosos do tema e sindicalistas que decidiram criar um fórum de debate e combate à terceirização: o Fórum Permanente em Defesa dos Trabalhadores Ameaçados pela Terceirização. ${ }^{6}$

Nos últimos quatro anos, o fórum tem tido uma atuação incansável contra todas as tentativas de liberar a terceirização no Brasil, especialmente contra o PL 4.330, organizando seminários, debates, manifestações, manifestos, abaixo-assinados e mais recentemente, em 2015, a realização de 27 audiências públicas em todas as capitais brasileiras, em parceria com a Comissão de Direitos Humanos do Senado, coordenada pelo senador Paulo Paim.

As principais centrais sindicais também aderiram à campanha contra o PL 4.330, manifestando-se nas ruas, nas redes sociais, nos sindicatos, em greves e na imprensa, num processo que colocou na pauta da grande imprensa o debate acerca da terceirização, denunciando para a sociedade o quanto ela é perversa e precarizadora do trabalho. Esse movimento, apesar de não ter impedido a aprovação do projeto de lei pela Câmara de Deputados - dada a forma autoritária de atuação do seu presidente, que impediu a discussão em plenário -, criou uma situação de constrangimento a outra instância do Congresso Nacional, o Senado, cuja Comissão de Direitos Humanos decidiu realizar uma ampla discussão com a sociedade brasileira - por meio das audiências públicas antes de colocar o projeto em votação. E é isso que tem sido feito até o momento, apesar das pressões das instituições, partidos e representantes do patronato para que o PL 30 seja votado.

Entretanto, em meio à ampla mobilização contra o PL 4.330, em abril de 2015, o Supremo Tribunal Federal julgou a ADI 1.923 sobre as OSs. Em fevereiro ela (a ADI) foi colocada em pauta e imediatamente julgada sem alarde (Souto Maior, 2015), referendando que tudo o que está sendo feito na área de saúde é constitucional e pode ser implantado em todo o serviço público. Trata-se da liberalização da terceirização para atividades 'finalísticas' do Estado, cuja experiência, relatada pelo TCU, nega absolutamente o dever constitucional do Estado no Brasil. De acordo com Souto Maior:

A lógica privatista do Estado, que permite uma enorme promiscuidade com o setor privado, no entanto, foi acatada pelo Supremo, segundo explicitado no voto: “Na essência, preside a execução deste programa de ação institucional a lógica, que prevaleceu no jogo democrático, de que a atuação privada pode ser mais eficiente do que a pública em determinados domínios, dada a agilidade e a flexibilidade que marcam o regime de direito privado." (Souto Maior, 2015) 
Essa decisão avaliza e incentiva a generalização do uso das organizações sociais para todos os serviços públicos no país na forma como vêm ocorrendo, isto é, como constatou o TCU, sem nenhum limite, sem nenhuma regulação, sem nenhum controle, em desrespeito a toda a legislação pertinente, num claro processo de privatização dos serviços públicos e de precarização do funcionalismo e dos trabalhadores que os substituem, como de 'segunda categoria', terceirizados numa condição sem direitos, sem vínculos permanentes e sem qualquer critério objetivo de seleção. Na realidade, a decisão do STF pode levar ao fim dos concursos públicos para as áreas sociais do governo, cuja implicação, a médio prazo, será a progressiva extinção do funcionalismo público e, consequentemente, da natureza pública dos serviços sociais de que a sociedade necessita e aos quais tem direito.

No caso da educação, a situação também é grave. Atualmente o crescente processo de terceirização dos serviços ditos não essenciais, como é o caso da limpeza, vigilância, manutenção, portaria e outros, tem demonstrado um grau profundo de precarização do trabalho. As empresas que prestam esses serviços às universidades públicas, por exemplo, desrespeitam sistematicamente os direitos desses trabalhadores, a exemplo do atraso de salários e vales-transporte e alimentação, o não pagamento de $13^{\circ}$ e de férias, o não depósito do Fundo de Garantia por Tempo de Serviço (FGTS). Contra essa situação, tem ocorrido greves desses trabalhadores terceirizados, momento em que se tornam visíveis para a sociedade, e para as próprias universidades, pois a ausência desses serviços leva à paralisação das instituições, como ocorreu nas universidades federais do Rio de Janeiro, Fluminense e da Bahia, evidenciando como são essenciais para a atividade pública, e que, portanto, deveriam fazer parte do corpo do funcionalismo, como era antigamente (Santana e Druck, 2015).

Essas empresas prestadoras de serviços são contratadas por intermédio da Lei de Licitações, diferentemente das OSs, que não estão subordinadas a licitações nem para serem contratadas pelo Estado, nem para subcontratar os trabalhadores que prestarão os serviços. E, ainda que selecionadas por meio de licitações, essas empresas (contratadas pelo menor preço) em geral não possuem situação financeira estável, e para garantir o seu preço, economizam no pagamento dos direitos e dos salários dos trabalhadores - aqueles que sofrem as penalidades que as universidades exercem, suspendendo contratos e pagamentos, ao descobrirem a inadimplência das terceiras. É o círculo vicioso da precarização do trabalho dos terceirizados no serviço público em instituições onde estão os mais importantes intelectuais do país, onde se produz ciência e pesquisa e onde se preparam novas gerações de profissionais de todas as áreas.

Em 2015, o governo de Dilma Rousseff, além de suspender a reestruturação das universidades, paralisando até mesmo obras já iniciadas, deter- 
minou o corte de verbas para educação como parte do contingenciamento/ajuste fiscal, reduzindo drasticamente as verbas para custeio e congelando os recursos para investimentos. Com isso, criou-se uma situação de estrangulamento das universidades, pois entre $80 \%$ e $90 \%$ das despesas de custeio são para pagamento da prestação de serviços terceirizados. Assim, o corte de custeio atinge diretamente os trabalhadores terceirizados. Em várias universidades federais do país, as aulas e atividades foram suspensas porque os serviços de portaria, vigilância e limpeza estavam paralisados por falta de pagamento de salários - uma clara demonstração de que, sem esses serviços, a universidade não funciona (Santana e Druck, 2015).

Esse quadro das universidades federais foi o principal motivo que levou ao movimento grevista de docentes, estudantes e servidores técnicoadministrativos em 2015, cuja pauta principal era a defesa da universidade pública e contra os cortes na educação.

No caso das universidades públicas, as OSs já existem na forma de fundações, contribuindo para dar um caráter operacional à universidade, voltada para atender as necessidades do mercado (Chauí, 2001), com o financiamento de cursos pagos e a contratação de professores por disciplina, ou por aula ou por curso de um semestre; em contraposição à instituição pública, cuja vocação é produzir conhecimento por meio das pesquisas, realizar um ensino de qualidade e praticar atividades de extensão junto da sociedade. Até hoje, a mobilização em defesa dessa universidade pública conseguiu barrar a proliferação das OSs, mas com a decisão do STF, somada ao corte de verbas que terá efeitos sobre o número de concursos públicos para docentes, a tendência será utilizar essa forma de terceirização e de precarização do trabalho.

A terceirização de docentes será um impeditivo para qualquer trabalho acadêmico, pois os professores contratados para aulas não terão nenhuma oportunidade, nem responsabilidade, para desenvolver atividades de pesquisa e extensão. As universidades se transformarão, aos poucos, em escolas de terceiro grau, perdendo seu caráter de lugar de reflexão, aprendizagem, experiência, inovação e criatividade.

\section{As universidades federais e a terceirização dos hospitais universitários: uma 'OS pública com fins lucrativos' - a Empresa Brasileira de Serviços Hospitalares}

Além dessas formas de terceirização nas universidades públicas, cabe mencionar, no caso das instituições federais de ensino, a criação pelo governo federal, em 2011, pela lei $n^{\circ} 12.550$, da EBSERH. É uma empresa pública com personalidade jurídica de direito privado e patrimônio próprio, vinculada ao Ministério da Educação e responsável pela gestão do Programa Na- 
cional de Reestruturação dos Hospitais Universitários Federais (Rehuf), criado em 2010.

A justificativa para a criação desse programa era sanar a crise dos hospitais universitários, considerados sucateados em termos de equipamentos e tecnologia e, principalmente, pela falta de funcionários. Essa situação levou muitos hospitais à contratação de trabalhadores por intermédio de fundações universitárias, provocando dívidas trabalhistas e intervenção do Ministério Público do Trabalho, que considerou esse processo de terceirização ilícito.

A EBSERH é dotada de recursos do orçamento da União e de outras receitas provenientes de prestação de serviços, alienação de bens e direitos, aplicações financeiras, direitos patrimoniais sobre bens, acordos e convênios com entidades nacionais e internacionais, doações que lhe forem destinadas e rendas oriundas de outras fontes. Tem por finalidade

[...] a prestação de serviços gratuitos de assistência médico-hospitalar, ambulatorial e de apoio diagnóstico e terapêutico à comunidade, assim como a prestação às instituições públicas federais de ensino ou instituições congêneres de serviços de apoio ao ensino, à pesquisa e à extensão, ao ensino-aprendizagem e à formação de pessoas no campo da saúde pública, observada, nos termos do art. 207 da Constituição Federal, a autonomia universitária. (Brasil, 2012, p. 10).

Porém, além da prestação de serviços gratuitos no âmbito do SUS, a EBSERH poderá atender planos privados de saúde. Conforme o artigo $3^{\circ}$, parágrafo $3^{\circ}$ da lei $\mathrm{n}^{\circ} 12.550$, é permitido a essa empresa “o ressarcimento das despesas com o atendimento de consumidores e respectivos dependentes de planos privados de assistência à saúde, na forma estabelecida pelo art. 32 da lei $n^{\circ}$ 9.656, de 3 de junho de 1998" (Brasil, 2012, p. 10). É importante lembrar que o ressarcimento aos planos de saúde é praticado no âmbito do SUS de um modo geral, ou seja, respaldado pela lei $\mathrm{n}^{\circ} 9.656$, de 3 de junho de 1998. Apesar de reconhecidamente polêmico, esse ressarcimento foi ainda regulamentado pela Agência Nacional de Saúde Suplementar (ANS) por meio da resolução normativa $\mathrm{n}^{\circ} 358$, de 27 de novembro de 2014, e pela ins trução normativa Dides $n^{\circ}$ 54, de 27 de novembro de 2014, de sua Diretoria de Desenvolvimento Setorial.

Na constituição dos seus órgãos de direção, a quase totalidade dos seus membros nos diversos conselhos (administração, fiscal e diretoria executiva) é indicação do governo federal, tendo acento um representante da instituição federal indicada pela Associação Nacional de Dirigentes de Instituições de Ensino Superior (Andifes) e um representante dos funcionários no Conselho de Administração. A direção (Conselho de Administração) da EBSERH é constituída por sete membros indicados pelo governo, inclu- 
sive seu presidente; um integrante indicado pela Andifes; e um representante dos funcionários da empresa. Além do conselho, a EBSERH conta com uma Diretoria Executiva cujos membros também são escolhidos pela Presidência da República, por indicação do ministro da Educação. Há ainda um Conselho Fiscal, também constituído por indicação do governo, e um Conselho Consultivo, presidido pelo presidente da empresa, que tem por finalidade: consulta, controle social e apoio à Diretoria Executiva e ao Conselho de Administração. Esse conselho constituído por três representantes do governo (dos ministérios da Educação e da Saúde); um representante dos usuários dos serviços, indicado pelo Conselho Nacional de Saúde; um representante dos residentes de hospitais universitários, indicado por entidade representativa; um representante dos trabalhadores em hospitais universitários administrados pela EBSERH, indicado pela entidade representativa; e um reitor ou diretor de hospital, indicado pela Andifes.

A estrutura da EBSERH e suas finalidades explicitam que ela é uma empresa pública com fins lucrativos que irá apropriar-se de todo o patrimônio físico e de conhecimento de um hospital universitário, alijando as universidades federais de sua gestão. Essas, ao decidirem aderir à EBSERH, renunciam ao controle dos hospitais em troca de recursos públicos e contratação de pessoal fora do Regime Jurídico Único (RJU), para 'salvar' os hospitais universitários. Foi a pressão das condições de crise financeira e de pessoal que levou 37 hospitais universitários, de um total de 50 existentes no país, a aderirem a EBSERH e hoje serem geridos por ela. ${ }^{7}$

Um dos questionamentos centrais é se o problema principal era a falta de recursos financeiros para sanar a crise nos hospitais universitários, por que criar uma empresa pública, cujos recursos são públicos, parte do orçamento federal? Por que esses recursos não foram investidos diretamente pelo governo nas universidades federais que criaram e sustentaram esses hospitais? A resposta não é simples, mas a tese aqui defendida é de que essa é mais uma iniciativa no sentido de reduzir - com vistas à extinção - uma categoria profissional: o funcionalismo público, pela terceirização. Por isso, o regime de trabalho do pessoal permanente será celetista, selecionado por concurso público de provas ou de provas e títulos, assim como a contratação de pessoal será por tempo determinado, com contratos temporários por dois anos, prorrogáveis desde que não ultrapassem cinco anos.

Além disso, há ainda no artigo 48 do regimento da empresa a seguinte disposição:

Integram o quadro de pessoal da sede da EBSERH os ocupantes dos cargos de presidente e diretor estabelecidos no estatuto da empresa; os cargos ou funções gratificadas; os empregados públicos admitidos na forma do art. 10 da lei $\mathrm{n}^{\circ}$ 12.550, de 15 de dezembro de 2011 e os servidores públicos requisitados de outros órgãos (Brasil, 2012, p. 66; grifos meus). 
O caso da Universidade de Brasília (UnB) é ilustrativo das implicações dessa constituição híbrida do quadro de pessoal. Em 2015, na greve dos servidores públicos federais, o sindicato dos servidores da UnB expôs a situação:

Um dos principais problemas gerados aos servidores do HUB com a entrada da EBSERH foi o aumento da jornada de trabalho. Os trabalhadores cumpriam jornada de 6 horas diárias há cerca de 10 anos. Entretanto, o regime de trabalho da EBSERH é regido pela Consolidação das Leis do Trabalho - CLT, que determina jornada de trabalho de 8 horas diárias. A mudança de horário não foi totalmente implementada no HUB, mas já dá sinais com o aumento do número de plantões, trabalho em recessos e feriados, realidade que já atingiu a maioria dos servidores do quadro do Hospital (Sindicato dos Trabalhadores da Fundação UnB, 2015).

Ainda na mesma notícia, o dirigente sindical informa que: "Servidores do HUB que não querem continuar no hospital sob a gestão da EBSERH estão tendo dificuldade para serem realocados. Já os que não querem sair do hospital, temem ser cedidos arbitrariamente" (Sindicato dos Trabalhadores da Fundação UnB, 2015). Essa situação já era prevista em 2012, quando da realização do Seminário Nacional de Hospitais Universitários, em Brasília, no qual o debate central foi sobre a EBSERH, em seus aspectos políticos e jurídicos. Em carta aberta redigida no seminário, houve manifestação contrária, afirmando ser a EBSERH uma forma de privatização: “Tratase de parte de um projeto maior de como os diversos governos estão modificando o Estado brasileiro, na lógica da privatização e das parcerias público-privadas" (Seminário Nacional de Hospitais Universitários, 2012).

Nessa mesma carta, era denunciado que a EBSERH é

[... um processo que desmonta todo o sistema de ensino, pesquisa e extensão na área da saúde, colocando ainda todo o patrimônio público a serviço das grandes empresas que já exploram o setor. Isso sem contar com a quebra do atendimento de ponta que é realizado por esses hospitais, que são referência em diversas especialidades e atendem respeitando os princípios do SUS. Para além disso, a adesão à EBSERH representa um grave ataque à autonomia administrativa, didático e científica - prevista no artigo 207 da CF [Constituição Federal] - que coloca em risco a soberania nacional (Seminário Nacional de Hospitais Universitários, 2012). 
E alertava sobre a precarização das relações de trabalho, dado que:

Os contratos de trabalho serão celetistas sem estabilidade onde a rotatividade de profissionais além de não garantir a formação adequada dará um caráter descartável ao trabalhador e será prejudicial ao bom desenvolvimento dos serviços de educação e saúde (Seminário Nacional de Hospitais Universitários, 2012).

Posição similar encontra-se desde 2011 em cartas de repúdio do Conselho Nacional de Saúde, referendando decisão da XIV Conferência Nacional de Saúde. A crítica à EBSERH ressalta que a "precarização, resultante do processo de terceirização, é um mal para o serviço público, por se constituir, na maioria, em um canal de corrupção, de clientelismo, de nepotismo, de baixa qualidade nos serviços públicos prestados à população" (Conselho Nacional de Saúde, 2012). Além disso, considera que o processo de terceirização dos hospitais realizado pela EBSERH é inconstitucional, uma vez que se trata da terceirização de atividades-fim do Estado. Destaca também que os funcionários da EBSERH serão contratados pela CLT, quando o acórdão do TCU/2006 havia determinado a substituição do pessoal terceirizado dos hospitais universitários por servidores contratados pelo Regime Jurídico Único.

Em 2015, foi decidida uma greve nacional dos funcionários da EBSERH, cujas principais reivindicações eram jornada de trabalho de $12 \times 36$ horas para todos os empregados da empresa, com uma hora de descanso dentro da jornada; garantia de que $1 \%$ da folha geral da empresa fosse destinada para fins de progressão e titulação; participação dos empregados na criação das normas para garantir paridade nas decisões; e garantia dos 7,7\% de reajuste salarial e em todos os benefícios.

Nesse mesmo ano, realizou-se um novo Seminário Nacional dos Hospitais Universitários, três anos depois do início da implantação da EBSERH. ${ }^{8}$ Na oportunidade, o presidente em exercício da EBSERH declarou que houve uma diminuição de 2.800 servidores em RJU devido a aposentadorias, falecimentos e desistências. E que cada servidor em RJU que saísse seria substituído por um celetista. Ainda segundo o presidente, "a tendência é aumentar o número de trabalhadores celetistas e diminuir o número de servidores RJU pela política de Estado que já há algum tempo é vigente no país" (Federação de Sindicatos de Trabalhadores Técnico-Administrativos em Instituições de Ensino Superior Públicas do Brasil, 2015), situação que já ocorre, pois atualmente são 17.992 trabalhadores em RJU e 18.266 celetistas concursados nos hospitais universitários, segundo informações do próprio presidente da EBSERH. Entretanto, apesar dessa ênfase nos traba- 
lhadores celetistas, é de conhecimento público, destacada também pela Federação de Sindicatos de Trabalhadores Técnico-Administrativos em Instituições de Ensino Superior Públicas do Brasil (Fasubra), a terceirização nos hospitais universitários por meio da EBSERH:

Nos hospitais se usa grande parte do custeio para pagar terceirizados, contratação de serviços fechados como setores de nefrologia, fisioterapia, nutrição, limpeza, cozinha, segurança, e outros. O trabalho precarizado continua e com baixíssima qualidade. A EBSERH tem que saber a realidade dos hospitais cedidos, a gestão que era para melhorar, não melhorou, pelo contrário, continuam os problemas, a precarização, aumento do adoecimento dos trabalhadores e casos de assédio (Federação de Sindicatos de Trabalhadores Técnico-Administrativos em Instituições de Ensino Superior Públicas do Brasil, 2015).

A forma híbrida dos vínculos de trabalhadores em RJU 'cedidos' à EBSERH e de celetistas tem gerado problemas diversos: nas relações entre os próprios trabalhadores, criando um ambiente de disputa entre eles, e na representação sindical de uns e outros, fragmentando a sua organização, conforme expõe a Fasubra:

A forma de constituição dos contratos fere a legislação, são heterogêneos. A Fasubra fez um levantamento nacional de todos os contratos nas universidades que aderiram à EBSERH. A Universidade Federal do Rio Grande - RS foi a única que tratou de alguns elementos da carreira com relação aos trabalhadores cedidos. Em outras universidades, os trabalhadores foram cedidos sem consulta, não puderam opinar, sem nenhum elemento no contrato que garantisse os direitos como: política de capacitação, política de avaliação, carga horária e outros. Nós queremos debater isso com a EBSERH [...]. E não só apenas discutir a situação dos trabalhadores cedidos, mas também dos trabalhadores da EBSERH, que são trabalhadores da universidade. E quem representa os trabalhadores das universidades é a Fasubra e não uma outra confederação que está representando agora os trabalhadores da EBSERH, como também representamos os trabalhadores das fundações, das empresas terceirizadas das áreas de vigilância e limpeza. Todos são trabalhadores da universidade (Federação de Sindicatos de Trabalhadores Técnico-Administrativos em Instituições de Ensino Superior Públicas do Brasil, 2015).

Em 2012, a Frente Nacional Contra a Privatização da Saúde, em manifesto em defesa do caráter público dos hospitais universitários e contra a EBSERH, já destacava a sua inconstitucionalidade, alertando sobre a cessão de servidores públicos para a empresa: 
A desobediência à Constituição, na lei no $12.550 / 2011$, se estende ao prever, no artigo $7^{\circ}$, a cessão de servidores públicos para a EBSERH com ônus para a origem (órgão do Poder Público). Esta cessão é inadmissível à luz dos princípios mais elementares do direito, assim como obriga os servidores à prestação de serviços a entidades com personalidade jurídica de direito privado, quando foram concursados para trabalharem em órgãos públicos. Esses servidores, muitos deles qualificados com especializações, mestrados e doutorados, passariam a ter cargahorária, processos de trabalhos e de gerência determinados e controlados pela empresa, que também passaria a definir metas e produtividade (Frente Nacional Contra a Privatização da Saúde, 2012).

\section{Algumas considerações finais}

Compartilhamos com os estudiosos que afirmam ser a terceirização no serviço público uma forma de privatização, um processo decorrente de uma política que transforma a natureza do Estado e de sua intervenção. Não se trata de banir o Estado, pois nenhuma sociedade capitalista e de classes sobrevive sem ele, e isso está comprovado historicamente nos regimes liberais ou neoliberais, pois a atuação do 'poder público' é fundamental para garantir a fetichização do mercado.

Assim, quando os bens públicos como saúde e educação, por exemplo, tornam-se cada vez mais mercantilizados, por conta da existência de um mercado quase ilimitado, já que toda sociedade tem necessidade desses bens, a atuação do Estado, por meio das suas políticas, torna-se fundamental para retirar ou reduzir o acesso à saúde e educação públicas como direitos sociais e humanos. E são essas políticas que estão em curso no Brasil desde o início dos anos 1990. O Estado brasileiro - por intermédio de diferentes governos que se sucederam - aderiu e vem se transformando num típico modelo de um Estado neoliberal - não sem contradições, tensões e resistências, conforme já demonstrado anteriormente, mas o que se quer destacar nesse processo é a centralidade que ocupa o trabalho e suas transformações. A terceirização no serviço público - nas mais diversas formas, como as OSs, as Oscips, as empresas privadas, as empresas públicas de direito privado, as parcerias, dentre outras - é o meio principal para atacar o coração de um Estado social e democrático: os trabalhadores que constituem o funcionalismo público.

As informações aqui sistematizadas são indicadores de um processo de generalização da precarização do trabalho, ao qual me refiro para explicar um dos aspectos da sua natureza social, qual seja, o de romper com determinadas dualidades, aqui representadas pelo público e privado, expresso em três momentos da terceirização no serviço público: 
a) a diminuição do número de funcionários públicos com a sua substituição crescente por funcionários terceirizados e não estatutários; b) a subordinação dos funcionários públicos que ainda permanecem à gestão privada, como é o caso da EBSERH, submetidos a piores condições de trabalho; e c) o crescente número de trabalhadores terceirizados com contratos precários, e, mesmo quando celetistas, sem vínculo permanente ou tendo seus direitos sistematicamente desrespeitados. Dessa maneira, funcionários públicos estatutários, celetistas, temporários são todos atingidos pela precarização, mesmo que de forma hierarquizada.

Ademais, a natureza social da precarização do trabalho no serviço público tem importante singularidade: por se tratar de uma força de trabalho cujo valor de uso é produzir bens públicos e, portanto, servir à sociedade, o seu rebaixamento ou a sua redução ou mesmo a sua extinção geram implicações imediatas e plenamente visíveis ao conjunto da sociedade, sem o fetiche da relação de assalariamento do setor privado que encobre a exploração do trabalho e a produção do lucro. Por isso, a mercantilização da saúde e da educação no interior do próprio Estado, pela terceirização, conforme visto, tem importância decisiva e estratégica para o capital, que, agora acobertado e acolhido nas entranhas do serviço público, não só conquista mais mercados, mas fetichiza também o trabalho no interior das instituições públicas.

A redução do efetivo de funcionários públicos estatutários, a quebra de direitos, a exemplo das reformas da previdência, a desvalorização salarial, a desqualificação e desmoralização da sua função e a sua submissão a formas de gestão privadas, somadas ao processo de terceirização constituem a força maior de uma ofensiva que tem por objetivo a extinção desse segmento de trabalhadores, pois a sua existência - enquanto força de trabalho vivo - é a única garantia para se manter algum caráter público de bens necessários à reprodução social dos trabalhadores em geral, como saúde e educação.

E, por isso, resistem. Sem essa resistência - com greves, manifestações de ruas, fóruns, seminários, debates, congressos, mobilização dos sindicatos e dos movimentos sociais os quais defendem que, sem a existência e a manutenção dos servidores públicos brasileiros, - a maioria da sociedade, constituída pelos segmentos mais pobres, já estaria totalmente destituída de direitos sociais fundamentais, como saúde e educação. 
Resumen Se presentan, en este ensayo, algunas reflexiones sobre la tercerización en el servicio público a partir de la óptica de la sociología del trabajo. Se toma como referencia la implantación de las organizaciones sociales, que se convirtió en fuerte realidad en la salud pública en los últimos 15 años, y que, a partir de 2015, por decisión del Supremo Tribunal Federal de Brasil, fue validada como constitucional, con lo que se negó el pedido de acción directa de inconstitucionalidad. De esa forma, fue liberada la tercerización para todos los servicios esenciales bajo responsabilidad del Estado. También es objeto de discusión la implantación de la Empresa Brasileira de Serviços Hospitalares, que, aunque más reciente que las organizaciones sociales, ya presenta resultados tan nocivos cuanto ellas. La tesis defendida es que la tercerización del servicio público en Brasil es uno de los mecanismos más eficientes de desmonte del contenido social del Estado y de su privatización, que ocurre mediante formas diversas de precarización del trabajo, pues la tercerización - por medio de organizaciones sociales, organizaciones de la sociedad civil de interés público, empresas privadas, empresas públicas de derecho privado, asociaciones, y otras es el medio principal que las fuerzas políticas neoliberales encontraron para atacar el corazón de un Estado social y democrático: los trabajadores que constituyen el funcionariado público.

Palabras clave tercerización; servicio público; organizaciones sociales; precarización del trabajo.

\section{Notas}

1 Universidade Federal da Bahia, Faculdade de Filosofia e Ciências Humanas, Departamento de Sociologia, Salvador, Bahia, Brasil.

$<$ druckg@gmail.com>

Correspondência: Universidade Federal da Bahia, Faculdade de Filosofia e Ciências Humanas, Estrada de São Lázaro, 197, CEP 40210-730, Salvador, Bahia, Brasil.

2 Dentre eles, registro: ARAÚJO, Anísio J. S., 2001; BORGES, Angela, DRUCK, Graça, 2002; BORGES, Angela; DRUCK, Graça, 1993; DEPARTAMENTO INTERSINDICAL DE ESTATÍSTICA E ESTUDOS SOCIOECONÔMICOS (DIEESE), 1994, 2008; DRUCK, Graça; FRANCO, Tânia, 2007; DRUCK, Graça, SANCHES, Ana T. 2009; AMORIM, Helder S., 2009; POCHMANN, Márcio, 2008 ANTUNES, Ricardo; DRUCK, Graça, 2013.

3 A Lei de Responsabilidade Fiscal determina um limite para a União de $50 \%$ da receita corrente líquida com despesas de pessoal do Estado e, para os estados e municípios, $60 \%$. Os contratados por OSs não são computados como despesa de pessoal.

4 No caso da Bahia, o “decreto estadual 9.322/2005, que instala o Conselho Gestor do Programa de Parcerias Público-Privadas do Estado da Bahia, a quem cabe supervisionar a fiscalização e a execução das parcerias público-privadas nos termos da lei estadual 9.290/2004, não prevê a participação de representantes da sociedade ou dos conselhos estaduais" (Tribunal de Contas da União, 2012, p. 58).

5 O tema da precarização do trabalho na saúde tem sido discutido e foi objeto do Seminário Nacional sobre Política de Desprecarização das Relações de Trabalho no SUS, realizado em 2003, e que teve o seu relatório publicado, assim como se fez presente nas Conferências de Saúde e nas Conferências de Gestão do Trabalho e da Educação em Saúde.

6 Ver: http://www.combateaprecarizacao.org.br/. 
7 Não aderiram à EBSERH as universidades federais do Rio de Janeiro, Fluminense, de Uberlândia, de São Paulo e de Santa Catarina.

8 Artigo publicado no Brasil de Fato, assinado por Viviane Tavares, da Escola Politécnica de Saúde Joaquim Venâncio/Fiocruz, informa, em 1\%/2/2014: “A Universidade Federal do Rio de Janeiro (UFRJ), que conta com o maior número de hospitais universitários do país, sete no total, é uma das grandes experiências de resistência. Como proposta alternativa ao modelo, docentes, técnicos administrativos e estudantes, em parceria com entidades representativas, elaboraram o documento "Proposta de modelo de gestão para o fortalecimento dos hospitais universitários" como proposta alternativa que aponta a continuidade da administração direta do Estado, mas enfatizando um aprofundamento da democratização da administração, um reforço da autonomia universitária e mais recursos. Em relação aos trabalhadores, eles apontam a contratação por meio do Regime Jurídico Único (RJU)." (Tavares, 2014).

\section{Referências}

ANDREAZZI, Maria F. S.; BRAVO, Maria I. S. Privatização da gestão e organizações sociais na atenção à saúde. Trabalho, Educação e Saúde, Rio de Janeiro, v.12, n. 3, p. 499-518, set./dez. 2014.

AMORIM, Helder S. Terceirização no serviço público: à luz da nova hermenêutica constitucional. São Paulo: LTr, 2009.

ANTUNES, Ricardo; DRUCK, Maria G. A terceirização como regra? Revista do Tribunal Superior do Trabalho, Brasília, v. 79, p. 214-231, 2013.

ARAÚJO, Anísio J. S. Paradoxos da modernização: terceirização e segurança dos trabalhadores em uma refinaria de petróleo. 2001. Tese (Doutorado em Saú de Pública)Escola Nacional de Saúde Pública Sergio Arouca, Fiocruz, Rio de Janeiro, 2001.

BORGES, Angela; DRUCK, Graça. Crise global, terceirização e a exclusão no mundo do trabalho. Caderno CRH, Salvador, n. 19, p. 22-45, 1993.

BORGES, Angela; DRUCK Graça. Terceirização: balanço de uma década. Caderno CRH, Salvador, n. 37, p. 111-139, 2002.
BRASIL. Presidência da República. Casa Civil. Subchefia para Assuntos Jurídicos. Lei Federal 9.637/1998. Dispõe sobre a qualificação de entidades como organizações sociais, a criação do Programa Nacional de Publicização, a extinção dos órgãos e entidades que menciona e a absorção de suas atividades por organizações sociais, e dá outras providências. Disponível em: <www. planalto.gov.br/ccivil_03/leis/L9637.htm>. Acesso em: 13 dez. 2015. Diário Oficial da União, Brasília, p. 42, 18 maio 1998.

BRASIL. Presidência da República. Lei $n^{\circ} 12.550$, de 15 de dezembro de 2011. Autoriza o Poder Executivo a criar a empresa pública denominada Empresa Brasileira de Serviços Hospitalares - EBSERH; acrescenta dispositivos ao decreto-lei no 2.848 , de 7 de dezembro de 1940 - Código Penal; e dá outras providências. Diário Oficial da União, Brasília, p. 2, 16 dez. 2011.

CHAUI, Marilena. Escritos sobre universidade. São Paulo, UNESP, 2001.

CONSELHO NACIONAL DE SAÚDE. Moção de Repúdio relativa à EBSERH, 12-13/set 2012. Disponível em: < http: //conselho.sa 
ude.gov.br/mocao/2012/mocao013.doc >. Acesso em: 10 dez. 2015.

DEPARTAMENTO INTERSINDICAL DE ES TATÍSTICA E ESTUDOS SOCIOECONÔ MICOS (DIEESE). O processo de terceirização e seus efeitos sobre os trabalhadores in Relações e Condições de Trabalho no Brasil. São Paulo, p. 73-147, 2008.

DEPARTAMENTO INTERSINDICAL DE ES TATÍSTICA E ESTUDOS SOCIOECONÔ MICOS (DIEESE). Os trabalhadores frente à ter ceirização. Pesquisa DIEESE, São Paulo, n. 7, 1993. 12 p.

DEPARTAMENTO INTERSINDICAL DE ES TATÍSTICA E ESTUDOS SOCIOECONÔMICOS (DIEESE). Terceirização e reestruturação produtiva do setor bancário no Brasil. Estudos Setoriais, São Paulo, n. 2, jul. 1994. 15 p.

DRUCK, Maria G. Terceirização: desfordizando a fábrica - um estudo do Complexo Petroquimico. Salvador: Edufba; São Paulo: Boitempo, 1999.

DRUCK, G; FRANCO, T. A perda da razão social do trabalho: terceirização e precarização. São Paulo: Boitempo, 2007.

DRUCK, Graça. Metamorfose e hierarquia da precarização social do trabalho no Brasil e reconfiguração da classe trabalhadora: a centralidade da terceirização e a condição social dos trabalhadores terceirizados. Projeto de Pesquisa. Bolsa de Produtividade em Pesquisa. Brasília: Conselho Nacional de Desenvolvimento Científico e Tecnológico (CNPq), 2014.

DRUCK, Graça. A terceirização no setor público e a proposta de liberalização da terceirização pelo $\mathrm{PL} \mathrm{n}^{\circ}$ 4.330. Jornal dos Economistas, Rio de Janeiro, n. 291, p. 11-13, out., 2013.

Empresa Brasileira de Serviços Hospitalares (EBSERH). Hospitais universitários federais, legislação, 2012. Disponível em: <http:// ebserh.mec.gov.br>. Acesso em: 15 jan. 2016.

FEDERAÇÃO DE SINDICATOS DE TRABALHADORES TÉCNICO-ADMINISTRATIVOS
EM INSTITUIÇÕES DE ENSINO SUPERIOR PÚBLICAS DO BRASIL (FASUBRA). Manifestação da Fasubra no Seminário Nacional de Hospitais Universitários. Brasilia, 7 dez. 2015. Disponível em: http://www.fasubra .org.br /index .php /fasubra/911-manifestacao-da-fasubrano-semina rio-nacional-dos-hospitais-universita-rios. Acesso em: 21 jun. 2016.

FRENTE NACIONAL CONTRA A PRIVATIZAÇÃO DA SAÚDE. Manifesto em defesa dos hospitais universitários como instituições de ensino pública-estatal, vinculadas às universidades, sob a administração direta do Estado: contra a implantação da empresa brasileira de serviços hospitalares nos hospitais universitários (HUs) do Brasil, 2012. Disponível em: <http://www. contraprivatizacao.com.br/2012/03/manifesto-contraebserh-leia-informe-se.html>. Acesso em: 1 fev. 2016.

INSTITUTO BRASILEIRO DE GEOGRAFIA E ESTATÍsTICA (IBGE). Perfil dos Estados e dos Municipios Brasileiros, 2014. Pesquisa de Informações Básicas Estaduais e Pesquisa de Informações Básicas Municipais (Munic), Rio de Janeiro: IBGE, 2014.

POCHMANN, Márcio. A Superterceirização do Trabalho. São Paulo: Ltr, 2008.

SANCHES, Ana T. Terceirização e ação sindical no setor financeiro. In: ENCONTRO NACIONAL DA ABET, 11. Anais ...Campinas: Abet, 2009.

SANTANA, Marco A.; DRUCK, Graça. A terceirização e a degradação do trabalho nas universidades brasileiras, São Paulo: Boitempo, Margem Esquerda, São Paulo, n. 25, p. 52-57, 2015.

SEMINÁRIO NACIONAL DE HOSPITAIS UNIVERSITÁRIOS. Carta aberta do Seminário Nacional de Hospitais Universitários. Brasília, 10 a 11 de novembro de 2012. Disponível em: <www.contraprivatizacao. com.br/2012/11/carta-aberta-do-seminarionacional-de.html>. Acesso em: 13 dez. 2015.

SINDICATO DOS TRABALHADORES DA FUNDAÇÃO UNB (SINTFUB). Últimas noti- 
cias: Comando local orienta servidores do HUB a formarem comissão de mobilização. Brasília, 2015. Disponível em: http:// www. sintfub.org.br/posts.php?id=6. Acesso em: 24 jun 2016.

SOUTO MAIOR, Jorge L. ADI 1.923: legitimação e ampliação da terceirização no setor público. In: GRUPO DE PESQUISA TRABALHO E CAPITAL. São Paulo: Faculdade de Direito da Universidade de São Paulo, 2015. Disponível em: https:// grupo depesquisatrabalhoecapital. wordpress.com /2015/04/22/. Acesso em: 21 jun. 2016.
THÉBAUD-MONY, A. Santé et travail: droit e pratiques $d u$ droit - Reflexions autour $d u$ role de l'État. In: APP A Y. B.: THÉBAUDMONY, A. (org.) Précarisation sociale. travail et santé. Paris: IRESCO. 1997. p. 143150.

TRIBUNAL DE CONTAS DA UNIÃO. $R e$ latório de Auditoria Operacional, TC 018. 739/2012-1. Brasília, 2012. Disponível em: http://www.tcu.gov.br/consultas/juris/doc s/judoc/acord/20131129/ac_3239_47_13_p. doc. Acesso em: 21 jun. 2016.

Recebido em 14/02/2016

Aprovado em 24/04/2016 